\title{
ORGANIZAÇÃO DE TRABALHO, CREDORA OU DEVEDORA? ESTUDO SOBRE RECIPROCIDADE ORGANIZACIONAL
}

Lilia Aparecida Kanan* José Carlos Zanelli\#

\begin{abstract}
RESUMO. Caracterizar a reciprocidade organizacional no contexto universitário por meio da percepção de docentes-gestores constituiu o objetivo desse estudo. A pesquisa assumiu caráter qualitativo com enfoque exploratório e descritivo e envolveu entrevistas semiestruturadas. Os participantes, docentes-gestores de universidades de Santa Catarina, manifestam que o reconhecimento e valorização dos esforços que despendem não constituem, ou pouco constituem, práticas gerenciais de seus superiores; suas expectativas de retribuição não são plenamente consideradas, o que reforça neles a percepção de débito de parte da universidade; mas, embora tais expectativas sejam frustradas, continuam a emitir atos inovadores, sugestivos e cooperativos, o que demonstra sua dedicação para com o curso e o trabalho, fato explicado pelo seu grau de comprometimento com a organização que os emprega.

Palavras-chave: Vínculos no trabalho; reciprocidade organizacional; docentes-gestores.
\end{abstract}

\section{WORK ORGANIZATION, CREDITOR OR DEBTOR? STUDY ABOUT ORGANIZATIONAL RECIPROCITY}

\begin{abstract}
Characterize the organizational reciprocity in the university context through to the perception of teachers-managers was aim of this study. The research took a qualitative approach with exploratory and descriptive focus and it involved semistructured interviews. The Participants, teachers-managers of universities of Santa Catarina, Brazil, show that the recognition and appreciation of the efforts they expend not constitute, or if so, they little appear as managerial practices of their bosses; their expectations of retribution are not fully considered; which reinforce in them the perception of debt by the university. But, although these expectations of reciprocity are frustrated, teachers-managers continue to deliver innovative, suggestive and cooperative acts, demonstrating their dedication to the course and with the work, a fact explained by their level of commitment to the organization that employs them.
\end{abstract}

Key words: Bonding process at work; organizational reciprocity; teachers-managers.

\section{ORGANIZACIÓN DEL TRABAJO, ACREEDDORA O DEUDORA? ESTUDIO SOBRE RECIPROCIDAD ORGANIZACIONALE}

RESUMEN. Caracterizar la reciprocidad organizacional en el ámbito universitario a través de la percepción de los profesoresadministradores constituyó el objetivo de este estudio. La investigación tuvo un enfoque cualitativo exploratorio y descriptivo, y envolvió entrevistas semi-estructuradas. Los participantes, profesores-administradores de las universidades de Santa Catarina, Brasil, demuestran que el reconocimiento y el aprecio de los esfuerzos no son o poco son prácticas de gestión de sus superiores; sus expectativas de reciprocidad no son plenamente consideradas, lo que refuerza su percepción de que hay deuda de parte de la universidad. Pero incluso si se frustran las expectativas, continúan ofreciendo acciones innovadoras, sugerente y de cooperación, lo que demuestra su dedicación al curso y la labor que se explica por el grado de compromiso con la organización que los emplea.

Palabras-clave: Relaciones en el trabajo; reciprocidad organizacionale; profesores-administradores.

Doutora em Psicologia pela Universidade Federal de Santa Catarina. Professora e pesquisadora PPGSC/Universidade do Planalto Catarinense, Brasil.

\# Doutor em Educação pela Universidade Estadual de Campinas. Professor adjunto IV da Universidade Federal de Santa Catarina, Brasil. 
Conflitos e problemas passaram a integrar de maneira mais intensa o cotidiano de uma significativa parte das organizações brasileiras, sobretudo a partir dos anos de 1990, uma vez que estas tiveram que lidar com ambientes complexos, marcados pela constante necessidade de mudanças e pela competitividade acirrada. Além de mudanças estruturais, funcionais ou tecnológicas a que foram submetidas, nas organizações de trabalho se tornou perceptível também a mudança de comportamento dos colaboradores: eles atualmente têm mais anos de estudos, estão mais críticos, conhecem mais sobre seus direitos contra tratamento injusto ou arbitrário, colocam em dúvida a autoridade e o modo como as coisas são feitas, levantam questões sobre sensibilidade nas decisões de suas chefias, exigem respeito e colocam ênfase nos valores humanos, preconizam a individualidade e a autoexpressão, além de outras características que podem ser atribuídas ao seu novo perfil. Tal cenário incita à necessidade de reordenamento e reorganização das atividades administrativas, principalmente as que envolvem a gestão de pessoas.

Em decorrência deste amplo processo de mudanças, muitos administradores perceberam a necessidade de considerar a subjetividade para a compreensão do comportamento humano no trabalho e se tornaram mais conscientes de sua importância, pois aspectos que a evidenciam transcendem $o$ prescrito, os contratos formais ou os regulamentos vigentes. Além disso, compreenderam que as expressões de sentimentos e emoções e as condutas e atitudes dos colaboradores são determinadas por muitos aspectos, entre eles os sociais, religiosos, políticos, econômicos e morais (Vergara, 2009).

Embora as mudanças no contexto organizacional tenham provocado alterações nas relações profissionais e sociais que nele ocorrem e a subjetividade tenha seu status ampliado, alguns fenômenos que determinam a qualidade destas relações permanecem sem a apropriada reflexão e pouco claros para os envolvidos. Reciprocidade organizacional, por exemplo, é um destes fenômenos que merece maior investimento da comunidade científica, em razão de ser significativo para a rotina dos processos intraorganizacionais de gestão de pessoas.

Não obstante, para que a compreensão do conceito de reciprocidade seja possível, é pertinente explicitar o conceito de obrigações mútuas. Conforme Robinson, Kraatz e Rousseau (1994), obrigações mútuas dizem respeito à percepção de dívida entre as partes, sendo esta crença originada das promessas de reciprocidade explícitas ou implícitas.

No contexto de trabalho, a todo o momento ocorrem comportamentos profissionais e sociais, muitos dos quais se relacionam às trocas implícitas ou explícitas entabuladas entre os integrantes da organização - as obrigações mútuas. Nas relações de troca, quem as protagoniza tem expectativas de reciprocidade (Eisenberger, Huntington, Hutchinson, \& Sowa, 1986). Destarte, uma dádiva e uma contradádiva estão presentes nessas relações (Polanyi, 1975), uma vez que uma unidade social se torna mais disposta a auxiliar outra quando esta última demonstra interesse em retribuir o benefício auferido (Gouldner, 1960).

Dádiva e contradádiva determinam, por exemplo, o fato de os colaboradores, neste sistema social, trocarem por salários ou outros benefícios o tempo e o esforço que despendem para realizar o trabalho. Em outras palavras, se por um lado a organização tem obrigações legais, morais e financeiras para com os colaboradores e deles espera comprometimento, lealdade e bom desempenho, por outro, os colaboradores têm a obrigação de ser comprometidos e leais com a organização e de apresentar bom desempenho. É a partir do contrato psicológico estabelecido entre a organização e o colaborador que se originam essas expectativas de trocas e benefícios mútuos. Difere o contrato psicológico do contrato legal e formal, o fato de que o primeiro pressupõe um relacionamento dinâmico, que mudará ao longo do tempo e está sujeito a constantes renegociações, enquanto que o segundo não enseja tais possibilidades. Sob esse aspecto, Rousseau (2001) destaca que o contrato psicológico representa o entendimento subjetivo do colaborador sobre a reciprocidade existente.

Referenciado deste modo, o contrato psicológico pode ser comparado ao princípio de reciprocidade de Gouldner (1960), em razão de envolver obrigações recíprocas. $\mathrm{O}$ autor traduz esse princípio em duas exigências sociais básicas: a) devemos ajudar a quem nos ajuda; b) não devemos prejudicar a quem nos beneficia. Para o autor, as relações sociais são orientadas por um princípio moral, aceito universalmente e não padronizado, que define como obrigação o ato de retribuir um favor recebido.

De outro modo, a lógica presente na percepção de reciprocidade organizacional é descrita por Siqueira (2005) de maneira a elucidar todo o processo: há situações em que o colaborador despende atos de trabalho, como, por exemplo, comportamentos espontâneos, inovadores, sugestivos, cooperativos, 
quando constata a necessidade de "oferecer ao seu empregador uma quota extra de trabalho, extrapolando suas obrigações formais ou aplicando um esforço extra para resolver situações problemáticas e/ou imprevistas que se apresentam em seu escopo de atuação na organização" (p.86). O colaborador vê esses atos como favores, benefícios ou ajuda à organização e, em decorrência disso, desenvolve crenças sobre futuras retribuições da organização a determinados atos seus de trabalho. Esses atos remetem-no ao papel de doador e a organização, ao de receptora. Prossegue Siqueira (2005), explicando que, como se sente doador para a organização em eventos passados, o colaborador acredita que, no futuro, a organização devedora retribuirá seus gestos sociais de ajuda sempre que ocorrerem problemas em sua vida pessoal e/ou profissional. Em outras palavras, quando, por exemplo, desempenha sua função, comparece ao trabalho, permanece na organização ou colabora espontaneamente, o colaborador revela algumas maneiras de manter relações de troca com seu empregador (Siqueira \& Gomide, 2004). Ademais, subjacente à ideia de troca, seja esta econômica ou social, também está presente no colaborador a expectativa de que a organização demonstre preocupação com seu bem-estar, e como recompensa de seus atos de trabalho, o colaborador espera que lhe sejam retribuídos os esforços que despende em favor da organização.

Siqueira (2005), por meio da abordagem cognitivista, sugere que os papéis de doador e receptor, no passado, eram "reorganizados mentalmente pelo empregado para alterar a sua posição e a da organização na relação de troca social: de doador, o empregado se reposiciona como credor, e atribui à organização o papel de devedora" (p.87). Estruturada a norma de reciprocidade na forma de um esquema mental, ela passa a se constituir num padrão cognitivo que possibilita ao colaborador ter expectativas de futuras retribuições por parte da organização.

Para ampliar a possibilidade de compreender este processo são destacados aqui alguns conceitos de reciprocidade organizacional: "(...) conjunto de crenças relacionadas à maneira como os empregados percebem a disposição da organização para emitir atos recíprocos" (Siqueira, 1995, p. 183); “(...) padrão de trocas mutuamente dependentes entre duas unidades sociais" (Oliveira, Pilati, \& Andrade, 1999, p. 32); “(...) crenças sobre retribuições da organização devedora, nutridas pelo empregado ao assumir o papel de credor durante uma troca social" (Siqueira, 2005, p. 87 ); norma social que caracteriza as interações sociais, apesar de não necessariamente estar presente em todas estas (Gouldner, 1960). A análise destes conceitos evidencia que eles guardam entre si aproximações epistemológicas importantes.

Depreende-se destes conceitos que eles são perpassados pela possibilidade de se extrapolar aquilo que está formalmente contratado. Katz, em 1964, já evidenciava que uma organização que depende exclusivamente de comportamentos prescritos é um sistema social muito frágil. A releitura desta evidência em relação ao contexto organizacional possibilita associá-la à realidade atual das organizações de trabalho, a qual requer de seus colaboradores respostas imediatas e espontâneas e criatividade diante das incertezas e das contingências. Não obstante, para que os colaboradores respondam com comportamentos que excedam ao prescrito é imperativo que percebam reciprocidade por parte da organização.

Ainda que o fenômeno reciprocidade organizacional, no Brasil, não predomine na agenda de pesquisas do comportamento organizacional, alguns autores (Siqueira, 1995; Oliveira, et al., 1999; Siqueira \& Gomide, 2004; Melo, 2006; B. Oliveira, 2006) oferecem importantes contribuições à compreensão do construto. Em alguns desses estudos a reciprocidade organizacional aparece como conceito transversal, mas são poucos aqueles nos quais o tema constitui o objetivo central do(s) autor(es). De maneira geral, a literatura acerca da reciprocidade organizacional ainda carece de aprofundamento científico e de maior visibilidade.

\section{MÉTODO}

A pesquisa, empreendida com o objetivo de caracterizar a reciprocidade organizacional, teve um caráter essencialmente qualitativo com enfoque exploratório e descritivo. Foram realizadas entrevistas semiestruturadas com dez docentes-gestores de cursos de Psicologia lotados nos campi sedes de todas as universidades do Estado de Santa Catarina que na época da coleta de dados ofereciam esse curso: nove universidades privadas e uma pública. $\mathrm{O}$ procedimento associado à técnica de entrevistas foi a recorrência.

A recorrência é um procedimento de coleta de informações pouco utilizado nas pesquisas de natureza qualitativa. Sobre o procedimento, Zanelli (1992) destaca que o:

Processo de interpretação e encadeamento dos conteúdos toma os relatos na forma de transcrições como ponto de partida. O recorte e composição das matrizes de encadeamento 
de conteúdos são realizados por meio de inferências do pesquisador e checadas pelo participante. (p. 67)

Este procedimento possibilita a checagem do próprio agente de verbalização daquilo que é inferido pelo pesquisador, e isso representa maior segurança quanto à composição dos fatores que o participante pretende associar ao problema (Zanelli, 1992). Em outras palavras: o participante relata livremente ao pesquisador aspectos associados ao problema. Estes relatos são sintetizados pelo pesquisador e incluídos em matrizes de análise. Em novo encontro entre pesquisador e participante, este último checa as matrizes que contém a síntese e a interpretação dada pelo pesquisador aos relatos do participante, corroborando-as ou refutando-as. Cada modificação sugerida pelo participante nas matrizes exige agendamento de novo encontro para que este possa checá-las. O processo se dá por encerrado quando o pesquisador e o entrevistado dão, consensualmente, por concluídas as matrizes, por se verem diminuídas as possibilidades de contribuição em função dos dados coletados.

Os instrumentos de coleta de dados utilizados nas observações foram criados em função da técnica de entrevista e do procedimento utilizados. A partir dos relatos verbais dos entrevistados, estimulados por conceitos-chave, foram criadas matrizes com $\mathrm{o}$ objetivo de facilitar aos participantes a identificação visual dos conteúdos que eles próprios forneciam. $\mathrm{Na}$ criação das matrizes havia uma configuração mínima a ser

obedecida, cuja finalidade era explicitar as relações.

Com referência nos pressupostos e definições formulados por Siqueira e Gomide (2004), o estudo procurou caracterizar a reciprocidade organizacional a partir das manifestações dos participantes em relação aos salários praticados, à ascensão funcional e promoções ou outras retribuições.

\section{RESULTADOS}

A seguir são apresentados os principais resultados da análise das variáveis que caracterizam a reciprocidade organizacional percebida por docentesgestores no contexto universitário.

\section{Reciprocidade organizacional associada a ascensão e salários}

Entre as obrigações da organização para com colaborador o salário é elemento de destaque, pois remete a avaliações sobre as necessidades do colaborador e o que o mercado de trabalho comumente oferece às pessoas que ocupam os mesmos cargos em organizações semelhantes. Sob esse enfoque, de forma geral, os participantes deste estudo avaliam que há "alguma" reciprocidade organizacional em termos de retribuições financeiras quando comparam o que eles percebem com o que pagam outras organizações semelhantes, mas consideram essas retribuições não condizentes com o cargo que ocupam. Para Zalewska (1999), as estruturas sociais são firmadas a partir de atitudes, percepções, crenças, motivações, hábitos e expectativas das pessoas que integram um grupo. Assim, a experiência no trabalho é permeada tanto de aspectos cognitivos (como as pessoas pensam o trabalho) quanto por aspectos afetivos (como as pessoas sentem o trabalho). Os participantes deste estudo manifestam que pensam e sentem o trabalho de maneira indissociada das retribuições percebidas: para alguns o trabalho representa mais esforços, para outros representa mais resultados. As conclusões registradas nos estudos de Prado (2005) e de Siqueira e Amaral (2006) confirmam a importância de considerar o salário e as possibilidades de promoção, ou as expectativas disto, para a determinação dos comportamentos dos colaboradores, pois, à medida que estes percebem que os benefícios recebidos da organização atendem às suas expectativas, podem ser neles desencadeados sentimentos de satisfação, comprometimento e reciprocidade em termos de desempenho. Ao contrário, o não atendimento das expectativas tem como efeito a "insalubridade psicológica”, o que representa risco para a saúde das pessoas e para os resultados da organização (Rego \& Souto, 2003).

As gratificações, promoções, benefícios, oportunidades de desenvolvimento e capacitação profissional, além dos salários, constituem maneiras de as organizações de trabalho retribuírem aos colaboradores e a todos os seus funcionários o que deles recebem. Para organizar a distribuição desses aspectos deve ser elaborado um plano de carreira, cargos e salário (PCCS) com base em critérios objetivos e conhecidos por todos os membros da organização. A percepção da existência de oportunidades de ascensão ou de possibilidade de receber os benefícios e gratificações contemplados no PCCS se traduz em condições favorecedoras para a ampliação dos esforços e maximização do desempenho. A maioria dos participantes expressa manifestações negativas em relação ao PCCS vigente 
na universidade: é desconhecido, inexiste ou não é praticado. Tal fato requer atenção, pois, conforme Siqueira e Amaral (2006), a insatisfação com a política de gestão de pessoas muitas vezes deriva do nível de satisfação dos colaboradores com o salário e as políticas de promoção.

Muito embora os salários dos participantes sejam compatíveis com o que oferece o mercado de trabalho, eles fazem uma avaliação negativa no que diz respeito ao atendimento de suas necessidades. Tal avaliação sobre a organização, conforme a maioria dos participantes, resulta de suas percepções desfavoráveis sobre as práticas nela vigentes. A percepção negativa das retribuições recebidas pelos participantes associada ao cargo ocupado se traduz em descontentamento e influencia tanto os fenômenos sociais quanto os fenômenos psicológicos decorrentes do esforço realizado ou do desempenho evidenciado.

Siqueira (2005) enfatiza que a função psicológica de um esquema mental de reciprocidade é possibilitar ao trabalhador a articulação mental de informações sobre seus papéis sociais de receptor e devedor na relação com a organização, haja vista as trocas sociais que ocorrem no contexto. Para a autora:

\begin{abstract}
Este esquema mental, por sua vez, se amplia quando o empregado assume o papel de doador, oferecendo gestos de colaboração espontânea à organização e desenvolvendo expectativas acerca de sua reciprocidade, se lembrando com maior clareza de ter sido doador e de ter a organização o dever de retribuir quando vivencia situações problemáticas para as quais necessitaria de apoio organizacional. (Siqueira, 2005 p. 92)
\end{abstract}

O princípio contido neste enunciado encontra reflexo nas manifestações de alguns docentes-gestores quando deixam explícita sua insatisfação pela inexistência de reciprocidade, por parte da universidade, no tocante às atividades que são "obrigados" a realizar fora do horário de trabalho pelas quais não são remunerados; todavia, mesmo diante de tais condições laborais adversas, todos os participantes expressam o desejo de permanecer na universidade. As oportunidades percebidas de crescimento profissional, os processos democráticos, a possibilidade de acessar conhecimentos, a trajetória na universidade e a carreira profissional são cognições que contribuem para a explicitação desse desejo e são aspectos considerados na avaliação que fazem da relação entre dádiva (aquilo que oferecem) e contradádiva (aquilo de que imaginam ser merecedores).
A explicação da continuidade da oferta de dádivas mesmo diante da percepção de inexistência ou insuficiência de contradádivas, encontra-se em Tamayo et al. (2001), segundo os quais existe uma motivação altruísta subjacente ao comprometimento organizacional. Essa motivação se manifestaria sua

disposição de investir esforços em favor da organização e de sua dedicação à mesma e ao bem-estar de todos os seus membros, particularmente, ao bem-estar decorrente da estabilidade da organização e preservação das tradições e das normas da mesma (p. 31).

\section{Reciprocidade organizacional associada a outras retribuições}

Poucas universidades envolvidas no estudo (a minoria) encontram maneiras próprias para retribuir os docentes-gestores. Essas retribuições estão associadas à possibilidade de estes participarem em eventos de atualização profissional, como congressos, simpósios, cursos, seminários e outros; porém não está claro para os docentes-gestores o real motivo deste tipo de retribuição, tampouco os critérios que o definem. A este respeito, é pertinente considerar que as oportunidades de capacitação, incentivo e avaliação motivam a aprendizagem contínua e esse esquema resulta em ampliação da satisfação e do desenvolvimento profissional dos colaboradores (Parrino, 2003; Rizzatti \& Rizzatti, 2005). Como a maioria das universidades não promove quaisquer situações de retribuição, segundo a avaliação dos participantes deste estudo, é possível verificar que, em geral, poucos docentes-gestores percebem iniciativas de valorização, aprovação e reconhecimento pelo seu desempenho. Esse fato é de certa gravidade, pois valorizar traz em seu escopo elementos associados a credibilidade, respeito e reconhecimento. Quando os colaboradores se sentem valorizados, agem com o propósito de retribuir a distinção recebida (Melo, 2006); no caso contrário, as probabilidades de maximização do desempenho são diminuídas.

Os poucos docentes-gestores que se manifestam em relação aos critérios utilizados na orientação do estilo retributivo deixam claro o desejo de que fossem objetivos, formalizados, e que os subjetivos associados a interesses pessoais - fossem eliminados. Sob esse aspecto, é evidente a importância da definição e utilização de critérios claros e conhecidos, pois um esquema de distribuição de recompensas ou de retribuições somente é considerado justo se precedido de procedimentos de escolha de critérios também justos (Rawls, 2008). As expectativas não cumpridas de reciprocidade associadas aos juízos de 
valor sobre os critérios praticados revelam a fragilidade dos acordos implícitos existentes no contexto das universidades.

Quando percebe que está doando para a organização, o docente-gestor acredita que, no futuro, a universidade devedora retribuirá seus gestos sociais de ajuda quando ocorrerem situações problemáticas em sua vida pessoal ou profissional (Siqueira, 2005); mas como isto efetivamente não acontece ou pouco acontece no contexto universitário, surgem as consequências: descontentamento e insatisfação decorrente do fato de perceberem inexistência ou insuficiência de iniciativas de reconhecimento e valorização pelo trabalho realizado. Os participantes colocam-se, assim, na condição de credores, por saberem que a universidade encontra-se em débito com eles.

\section{DISCUSSÃO}

É fato marcante a competitividade que caracteriza o contexto das universidades

nos tempos atuais. Cruz (2008) enfatiza que os avanços tecnológicos e as expectativas da sociedade quanto ao ensino superior promovem nestas organizações a necessidade de enfrentamento do ritmo acelerado de muitas mudanças. Para a autora, o governo tem mostrado indicativos de uma política de aumento do acesso de pessoas no ensino superior, mas tal política ou proposta ainda precisa superar resultados meramente quantitativos e concentrar esforços em mudanças qualitativas.

$\mathrm{O}$ conjunto de dados relativos à percepção de reciprocidade organizacional no contexto das universidades, conforme Cruz (2008), possibilita algumas considerações que explicam a realidade descrita pelos docentes-gestores. Por exemplo, a relação que se estabelece entre eles e a universidade é inicialmente de natureza contratual, e ao longo do tempo o processo de interação leva os primeiros a alterarem essa relação. Em função do ambiente social, esse processo passa a se caracterizar por fenômenos afetivos e emocionais e a impessoalidade normalmente é abandonada. A partir disto, o colaborador passa a representar mentalmente a organização como uma possível fonte de apoio e suporte à qual se une por laços de trabalho (Siqueira 2005). É intrínseco à universidade, por ser uma organização de trabalho, suas obrigações legais e financeiras para com os colaboradores e seus dirigentes terem a expectativa de que estes demonstrem bom desempenho, lealdade e comprometimento (Oliveira et al.,1999); todavia, as práticas de gestão, em busca do autossustento, não raro deixam de atentar para os aparatos sociais e para os múltiplos vínculos possíveis no contexto. Ao agir pela manutenção do estritamente prescrito, negando a importância ou limitando as relações de troca, os líderes relegam à condição de uma questão menor as expectativas dos colaboradores. Neste contexto, cumpre lembrar que os processos de gestão ou os modelos de desenvolvimento pessoal das universidades, quando não são orientados por diretrizes que considerem as cognições e os afetos dos colaboradores, levam a organização ao risco de a dinâmica social, a estrutura e a configuração dos contextos laborais sofrerem os impactos negativos desta omissão. Afinal, o contrato psicológico no trabalho mediado pelo entendimento subjetivo do indivíduo sobre a reciprocidade existente no relacionamento de troca entre ele e um terceiro está baseado nas promessas implícitas ou explícitas feitas no transcorrer dessa relação (Rousseau, 1995).

O princípio da reciprocidade engendra uma relação simétrica que, no caso das universidades, não ocorre ou pouco ocorre. Esse princípio compreende também a dádiva e a contradádiva, pressupondo certa proximidade entre os envolvidos. Assim, quanto maior for a proximidade, maior será a possibilidade de uma relação de reciprocidade (Polanyi, 1975). O que se observa, a partir das manifestações dos participantes, é a distância imposta pelos modelos de gestão, que pouco viabilizam autênticas parcerias.

É interessante observar que, apesar dos descontentamentos evidenciados em relação à reciprocidade, os docentes-gestores continuam a praticar atos de doação e a cumprir suas extensas jornadas de trabalho, algumas vezes sem receber remuneração pelas horas extras, dando respostas ao enorme volume de atividades que lhes cabe no exercício do cargo. Tais comportamentos encontram justificativas na extensão de seu envolvimento com o trabalho e com o cargo e no compromisso expresso com o êxito do curso, dos alunos e dos professores sob sua chefia. As oportunidades de crescimento ou conquistas profissionais decorrentes do cargo, a possibilidade de acessar conhecimentos e a avaliação que fazem dos custos e perdas diante de uma possível saída da universidade também justificam a manutenção desta relação desequilibrada e a contínua expressão e oferta de gestos de colaboração espontânea. É perceptível que, para alguns, permanecer na universidade está associado aos benefícios decorrentes dessa escolha, por isso fortalecem o vínculo com a universidade, vez que esta possibilita seu desenvolvimento profissional. 
Os docentes-gestores se comprometem com a universidade mesmo percebendo que ela está pouco comprometida com eles, e embora exija competência, criatividade, competitividade e polivalência de seus colaboradores, poucas vezes lhes oferece um suporte organizacional que promova satisfação no trabalho. Nas manifestações dos participantes está evidenciada a distância entre o que o docente-gestor espera e o que a universidade realiza.

Falhas no processo de servi-los, de atender suas necessidades e oferece-lhes o devido suporte prejudicam as percepções de que haja cuidado com seu bem-estar e valorização de seu trabalho, e apesar disso, os docentes-gestores mantêm crenças relativas à necessidade de retribuir os poucos benefícios recebidos. As expectativas sobre o que cada parte deve dar diante das contribuições da outra parte, as crenças relativas às maneiras como os colaboradores percebem a disposição da organização para emitir atos recíprocos (Siqueira, 2005), as obrigações mútuas que evocam uma percepção de dívida (Robinson et al., 1994) são maneiras semelhantes de conceituar o fenômeno reciprocidade organizacional. As expectativas, as contribuições, as crenças, a emissão de atos recíprocos e as obrigações mútuas são aspectos presentes nas manifestações dos docentes-gestores. A interpretação dessas manifestações e a tentativa de caracterizá-las sugerem que reciprocidade é um fenômeno que não ocorre em muitas universidades.

A explicação da última assertiva encontra-se nas políticas e estratégias de muitas das instituições de ensino superior, cujos líderes, embora não tenham preparo e sejam amadores, têm capital político suficiente para vencer eleições e, com frequência, esses são os "cultuados" (Meyer, 1998; Cardim, 2004). Muitos professores universitários pleiteiam cargos de direção porque são os que oferecem melhores salários e status. Como consequência, as universidades, não raro, têm em sua equipe diretiva um professor sem qualificação profissional para administrá-las, o que causa muito estranhamento, pois a maioria das profissões depende de diploma ou capacitação específica, mas dos dirigentes universitários isso não é exigido: basta ter qualquer curso de graduação para exercer esse tipo de trabalho (Botomé \& Kubo, 2002).

Depreende-se que os líderes universitários deveriam conhecer profundamente tanto os processos acadêmicos (aspectos pedagógicos), quanto as ferramentas de gestão administrativas (aspectos administrativos) (Strauhs, Andrade, \& Serafim, 2005). Pavan (2005) esclarece que a gestão das universidades necessita das características de liderança dos gestores, que, além de promover as mudanças necessárias, deveriam também saber capacitar seus funcionários e incentivá-los a serem multiplicadores. Leite (2005) argumenta que o líder deste contexto precisa ter uma visão estratégica para um bom desempenho administrativo, sendo uma de suas importantes habilidades a análise de todas as variáveis internas e externas que exercem influência sobre o trabalho; mas o fato é que a administração de muitas universidades, submetida a riscos e ao conservadorismo, processa-se de forma empírica, pois seus dirigentes carecem de conhecimentos teóricos sobre funções administrativas (Rizzatti \& Rizzatti 2005).

A interpretação das manifestações dos docentesgestores e a tentativa de caracterizá-las sugerem também que a retribuição e a distribuição de oportunidades ou de recursos são perpassadas, muitas vezes, por critérios subjetivos, de caráter pessoal e pouco claros ou conhecidos. Infere-se que no perfil dos gestores universitários as habilidades de negociação e barganha são imprescindíveis, mas estes, muitas vezes, em função de práticas de clientelismo e apadrinhamentos, tornam-se reféns de seu grupo de eleitores (Meyer, 1998).

É possível perceber ainda que, mesmo as expectativas de reciprocidade sendo frustradas, os docentes-gestores continuam a praticar atos espontâneos, fato que é explicado por seu comprometimento. Os docentes-gestores percebem débitos da universidade para com eles, mas lhes parece ser difícil acreditar na capacidade de doação da instituição. Esse elemento cognitivo pode ser a fonte de influência de muitas das manifestações de insatisfação evidenciadas.

Decorre deste fato que o processo de interação entre os docentes-gestores de curso e a universidade apresenta lacunas que promovem certo distanciamento entre os envolvidos. Há dissonância entre o que eles esperam e o que de fato recebem da organização como retribuição, dissonância que se acentua quando avaliam os esforços que despendem no cargo associados às suas expectativas de retribuição.

Os docentes-gestores de curso afirmam ainda que excedem o prescrito para seu cargo: respondem à sobrecarga de trabalho decorrente das contingências e incertezas próprias do curso que coordenam realizando atividades e horas extras que muitas vezes nem sequer são remuneradas. $\mathrm{O}$ descontentamento com a avaliação da reciprocidade organizacional evidenciado pela maioria dos docentes-gestores deriva da percepção de que seus esforços espontaneamente despendidos não são retribuídos. Se for considerado estritamente o que evidencia Katz (1964), é necessário 
refletir sobre a fragilidade das universidades enquanto um sistema social, pois elas têm, em sua maioria, instrumentos de descrição de cargo formalizados, no entanto exigem dos colaboradores o cumprimento de atividades muito além das obrigações contidas nos referidos instrumentos.

Outra reflexão possível enseja o entendimento de que as relações que ocorrem no contexto das universidades apresentam certas especificidades que merecem uma análise mais detalhada. Por serem a promoção e a produção de conhecimentos suas atividades-fim, em geral as universidades empregam pessoas que, em função de seu repertório de conhecimentos, via de regra têm atitudes e comportamentos que se traduzem em independência e autonomia. Por essas características, a reciprocidade de seus investimentos, a justiça percebida em termos de procedimentos e distribuição de recursos, o suporte organizacional às suas demandas e o comprometimento com a organização, entre outros, são aspectos que podem determinar sua permanência na organização. Talvez não seja por acaso que docentes e pesquisadores procuram se associar às universidades onde o respeito e a promoção dessas qualidades integrem as políticas e estratégias. Parrino (2003) analisou as razões da rotação de pessoal numa universidade e concluiu que, por vezes, ela perde colaboradores porque não satisfaz suas expectativas nem os motiva à permanência. Assim, um dos desafios com que se defrontam líderes universitários é a promoção da reciprocidade, da justiça, da satisfação, do comprometimento e do envolvimento de sua força produtiva, pois a atração e retenção de pessoas qualificadas dependem, em parte, de sua observância.

De todo modo, parece ser importante que nas políticas organizacionais prevaleçam condições que possibilitem a maximização do processo de vinculação entre colaboradores em todas as instâncias hierárquicas. Para que seja maximizado de modo a atrair e manter pessoas qualificadas, esse processo precisa considerar muitos fatores, entre eles a reciprocidade organizacional. Por meio das manifestações da maioria dos participantes, pôde ser observado que reconhecimento e valorização dos esforços despendidos não constituem práticas gerenciais de suas chefias e que suas expectativas de retribuição não são plenamente consideradas pelos líderes, o que reforça neles a percepção de débito por parte da universidade.

Ao encerrar esta discussão, é pertinente considerar que, dentre os participantes do estudo, apenas um pertence ao quadro de uma universidade federal. As características do trabalho e as relações que ocorrem no contexto das universidades públicas, acrescidas da segurança decorrente da estabilidade no emprego, exercem influência sobre o comportamento dos colaboradores desse tipo de organização. Há especificidades neste contexto que possibilitam aos colaboradores maior autonomia, liberdade e livre expressão. Tais aspectos podem ter influenciado as manifestações deste participante, mas suas manifestações e percepções se assemelham às dos demais, fato que não inviabiliza ou torna menores as conclusões do estudo.

Por fim, é possível transferir os resultados deste estudo para outros cursos de graduação, além dos cursos de Psicologia, e para outras universidades, além dos limites das universidades nas quais os participantes deste estudo trabalham. Recomenda-se, não obstante, que novas investigações sejam realizadas para que o conhecimento sobre o fenômeno possa ser aprofundado e ampliado. Sugerem-se, por exemplo, estudos que incluam uma amostra maior é os participantes de outros cargos gerenciais das universidades que não os dos docentes-gestores, pois poderão apresentar percepções diferentes ou complementares; que utilizem metodologias longitudinais e de abordagem qualitativa sobre o conjunto de variáveis que representam a reciprocidade organizacional; que examinem as relações existentes entre as variáveis que o estudo privilegiou; ou ainda, que examinem o poder preditivo da reciprocidade organizacional sobre a saúde e desempenho dos colaboradores e os resultados das organizações.

\section{REFERÊNCIAS}

Botomé, S. P., \& Kubo, O. M. (2002). Responsabilidade social dos programas de Pós Graduação e formação de novos cientistas de nível superior. Revista Interação em Psicologia, 6(1), 81-110.

Cardim, P. A. G. (2004). Gestão universitária em tempos de mudança. In Colombo, S. S. (Org.). Gestão educacional : uma nova visão. (pp. 323-337). Porto Alegre: Artmed.

Cruz, R. C. (2008). Tipos de atividades que constituem as rotinas de trabalho de diretores de cursos de graduação de uma universidade e aprendizagens para o exercício da função. Tese de Doutorado não-publicada, Programa de Pós Graduação em Psicologia, Universidade Federal de Santa Catarina, Santa Catarina, Florianópolis.

Eisenberger, R., Huntington, R., Hutchinson, S., \& Sowa, D. (1986). Perceived organizational support. Journal of Applied Psychology. 71(1), 500-507,

Gouldner, A. W. (1960). The norm of reciprocity: a preliminary statement. American Social Review, 25(2), 161-178.

Katz, D. (1964). The motivational basis of organizational behavior. Behavioral Science. 9, 131-133. 
Leite, D. D. (2005). Planejamento e gestão. Revista@aprender, 4(4), 34-41.

Melo, E. A. A. (2006). Vínculo do trabalhador com a organização: um estudo de representações sociais. Tese de Doutorado nãopublicada, Programa de Pós Graduação em Psicologia, Universidade de Brasília, Distrito Federal.

Meyer, V. (1998). Gestão para a qualidade e qualidade na gestão: o caso das universidades. Cadernos - Centro Universitário São Camilo, 4(1), 49-59.

Oliveira C. G. A., Pilati, R., \& Andrade, J. E. B. (1999). Percepção de suporte organizacional: desenvolvimento e validação de um questionário. RAC - Revista de Administração Contemporânea,3(2), 29-61.

Oliveira, B. (2006). Comprometimento organizacional: os impactos das percepções de cultura e suporte organizacionais. Dissertação de Mestrado não-publicada, Programa de Pós Graduação em Psicologia, Universidade Federal de Uberlândia, Uberlândia.

Parrino, M. C. (2003). Propuesta de Estrategias para la mejora de la gestión del personal académico. In Colóquio Internacional sobre Gestão Universitária na América do Sul, 3. [CD-ROM]. Buenos Aires.

Pavan, A. (2005). Competência coletiva. Revista Ensino Superior, 7(76), 22-25.

Polanyi, K. (1975). L'economie em tant que procès institutionnalisé. In K. Polanyi, \& C. Arensberg (Org.). Les systèmes économiques dans l'historie et dans la théorie. Paris : Larousse.

Prado, C. G. (2005). Investigando a saúde mental: as relações entre suporte organizacional, satisfação e sentimentos de prazer e sofrimento no trabalho. Dissertação de Mestrado não-publicada. Programa de Pós Graduação em Psicologia, Universidade Federal de Uberlândia. Uberlândia.

Rawls, J. (2008). Uma teoria da justiça. São Paulo: Martins Fontes.

Rego, A. (2003). Climas de justiça e comprometimento organizacional. Revista de Psicologia, Organizações e Trabalho, 3(1), 27-60.

Rizzatti, G., \& Rizzatti Jr, G. (2005). Categorias de análise de clima organizacional em universidades. In Colóquio Internacional sobre Gestão Universitária na América do Sul, 5. [CD-ROM]. Mar Del Plata.

Robinson, S. L., Kraatz, M. S., \& Rousseau, D. M. (1994). Changing obligations and psychological contract: a longitudinal study. Academy Management Journal, 37(1), 137-152.

Rousseau, D. M. (1995). Psychological contracts in organizations: understanding written and unwritten agreements. Thousand Oaks: Sage Publications.
Rousseau, D. M. (2001). Schema, promise and mutuality: The building blocks of psychological contract. Journal of Occupational Psychology, 74, 511-541.

Siqueira, M. M. M. (1995). Antecedentes do comportamento de cidadania organizacional: análise de um modelo pós-cognitivo. Tese de Doutorado não-publicada, Programa de Pós Graduação em Psicologia, Universidade de Brasília, Distrito Federal.

Siqueira, M. M. M. (2005). Esquema mental de reciprocidade e influências sobre afetividade no trabalho. Revista Estudos de Psicologia, 10(1), 83-93.

Siqueira, M. M. M., \& Amaral, D. J. A. (2006). Relações entre estrutura organizacional e bem-estar psicológico. REA-Revista Eletrônica de Administração, 5(1). Recuperado em 3 março, 2010, de http://www.facef.br/REA/edicao08/ed08_art03.pdf.

Siqueira, M. M. M., \& Gomide Jr, S. (2004). Vínculos do indivíduo com o trabalho e com a organização. In J. C. Zanelli, J. E BorgesAndrade, \& A.V.B. Bastos (Orgs.). Psicologia, organizações e trabalho no Brasil. (pp. 300-333). Porto Alegre: Artmed.

Strauhs, F. R., Andrade, M. M., \& Serafin, A. B. (2005) Perfil dos gestores das instituições de ensino superior privadas de Curitiba e região metropolitana. In Colóquio Internacional sobre Gestão Universitária na América do Sul, 5. [CD-ROM]. Mar Del Plata.

Tamayo, A., Souza, M. G. S., Vilar, L. S., Ramos, J. L., Albernaz, J. V., \& Ferreira N. P. (2001). Prioridades axiológicas e comprometimento organizacional. Psicologia: Teoria $e$ Pesquisa, 17(1), 27-35.

Vergara, S. C. (2009). Gestão de pessoas. São Paulo: Atlas.

Zalewska, A. M. (1999). Job satisfaction and importance of work aspects related to predominant values and reactivity. International Journal of Occupational Safety and Ergonomics, 5(4), 485-511.

Zanelli J. C. (1992). Formação profissional e atividades de trabalho: análise das necessidades identificadas por psicólogos organizacionais. Tese de Doutorado não-publicada. Programa de Pós Graduação em Educação, Universidade Estadual de Campinas, São Paulo.
Endereço para correspondência:
Av. Dom Daniel Hostin, 328, Bairro Frei Rogério, CEP 88.508-200, Lages-SC, Brasil. E-mail:1ak@uniplac.net.
Recebido em 17/04/2010

Aceito em 09/03/2011 